\title{
Are children meeting any of the suggested daily step recommendations?
}

\author{
Timothy A. Brusseau ${ }^{1}$, Catrine Tudor-Locke ${ }^{2}$, Pamela H. Kulinna ${ }^{3}$ \\ 1 University of Utah, ${ }^{2}$ Pennington Biomedical Research Center, ${ }^{3}$ Arizona State University, USA
}

\section{Summary}

Study aim: Over the past decade there have been numerous efforts to identify how many steps/day children should accumulate. Recommendations range from 10,000 to 16,500 steps/day. The purpose of this article was to examine the percentage of elementary school aged children meeting nine different sets of steps/day recommendations.

Material and methods: 786 Southwestern US children (410 girls, BMI 19.3 \pm 4.2 ) wore the Yamax Digiwalker SW200 pedometer and recorded their steps/day for 7 consecutive days. Mean steps/day was calculated and the percentage of students meeting each of the various steps/day recommendations was determined.

Results: Children averaged 11,113 $\pm 3,666$ steps/day. Sixty-one percent of all children met a minimum of 10,000 steps/day. Thirty-six percent met the most widely used recommendation of 11,000 and 13,000 steps/day for boys and girls, respectively. Using BMI referenced recommendations, between 10-52\% of children met various guidelines.

Conclusions: Southwestern US children in the current sample are not getting enough daily activity to meet the majority of step recommendations. Findings suggest that less than 33\% of children are active for 60 minutes of physical activity (inferred from one of the guidelines) a day and only 36\% would qualify for the Presidential Active Lifestyles Award. Additional school and home-based physical activity programming is clearly needed.

\section{Key words: Physical Education - Health - Pedometer - Physical Activity}

\section{Introduction}

Understanding the physical activity patterns of youth is an essential step in understanding the obesity epidemic and ultimately developing programs that reverse the trend [14].Over the past decade, pedometers have become a popular and widely used instrument for measuring youth physical activity due to their relative low cost and ease of use with the pediatric population $[1,3,4,5,6]$.
Recent reviews [1,25] of pedometer-based research studies have identified well over sixty pediatric publications using pedometers to identify youth step patterns. With this increase in use, numerous scholars have put forward steps/day recommendations. Identifying the prevalence of meeting these recommendations is important for practitioners and researchers who are interested in changing physical activity behavior. A list of the recommendations can be found in Table 1.

Table 1. Step recommendations

\begin{tabular}{ccccc}
\hline Recommendation & Boys & Girls & Population & Criteria \\
\hline Tudor-Locke et al.[24] & 10,000 & 10,000 & Japanese Men & Normative \\
Laurson et al. [15] & 11,500 & 10,000 & Midwest US Children & Normative \\
Colley et al. [8] & 12,000 & 12,000 & Canadian Children & 60 mins. MVPA \\
Vincent et al.[25] & 13,000 & 11,000 & Southwest US Children & Normative \\
Rowlands and Eston [22] & 13,000 & 12,000 & UK Children & 60 mins. MVPA \\
Tudor-Locke et al. [24] & 15,000 & 12,000 & US, Australian, Swedish Chil- & BMI Referenced \\
Duncan et al. [11] & 16,000 & 13,000 & New Zealand Children & Body Fat \% \\
Craig et al. [9] & 15,000 & 15,000 & Children from 12 Countries & 60 mins. MVPA \\
Craig et al. [9] & 16,500 & 16,500 & Canadian Children & 90 mins. MVPA
\end{tabular}


The recommendation of 10,000 steps/day can be traced back to the 1960's when Dr. Yoshiro Hatano established this recommendation for middle-aged Japanese men [24]. Today, this number is often used by the mass media as well as health professionals as an appropriate target for sufficient physical activity, at least for adults. Vincent and Pangrazi [27] determined that 11,000 (girls) and 13,000 (boys) steps/day was a reasonable standard for children. These recommendations were based on normative data collected from children (aged 6-12) living in the Southwestern US and have been regularly used by researchers around the world as a guideline to evaluate their data $[7,16]$. This recommendation was also originally adopted by the Presidential Active Lifestyle Award Program [18] (as of August 2012, the award criteria shifted to 12,000 steps/day for both boys and girls), a national award which requires children to accumulate 60 minutes of daily physical activity (or the equivalent in terms of steps/day) at least 5 days/week for 6 out of 8 weeks to qualify for the award.

Based on a comparison of concurrently worn accelerometers and pedometers, Rowlands and Eston [22] reported that 13,000 (boys) and 12,000 (girls) steps/day was representative (24 children aged 8-10) of sufficient moderate intensity physical activity (i.e., 60 minutes of moderate physical activity) within the course of daily activity. Duncan, Schofield, and Duncan [11] explored the weekday and weekend step counts of (ages 5-12) New Zealand children relative to body fat percent and determined that based on individual body fat percentages, 16,000 and $13,000 \mathrm{steps} /$ day were the optimal steps/day recommendation for boys and girls, respectively. Tudor-Locke and $[24,26]$ also examined how many steps are enough for children. They have suggested that 15,000 and 12,000 steps/day for boys and girls, respectively are appropriate recommendations based on a body mass index (BMI)referenced (determined by identifying normal weight and overweight/obese categories) criterion study of US, Australian, and Swedish children aged 6-12 [26].

Laurson and colleagues [15] in their evaluation of children's physical activity guidelines determined that the recommendation of 11,500 (boys) and 10,000 (girls) steps/day was most appropriate. They based this conclusion on their receiver operating characteristic analysis [15] and comparison of both the sensitivity and specificity of $[26,27]$ step recommendations to accurately categorize the steps/day of Midwest US children.

Furthermore, a recommendation of 15,000 steps/day (regardless of gender) has been used to examine the physical activity patterns of a large normative sample of youth participating in the Canadian Physical Activity Levels among Youth Study [9]. This recommendation is an interpretation by Craig and colleagues [9] of how many steps are required to accumulate at least 60 minutes of moderateto-vigorous physical activity (MVPA)/day and was based on how many steps are associated with physical activity time [2] and heart-rate measured physical activity [13]. Craig and colleagues [9] also highlighted the recommendation of 16,500 steps/day (regardless of gender) which is based on the Canadian Physical Activity Guide's interpretation of 90 minutes of MVPA [9]. Most recently, Colley, Janssen, and Tremblay [8] found 12,000 steps/day to be equivalent to 60 minutes of MVPA in children aged 6-19 who participated in the Canadian Health Measures Survey. The recent change in the President's Active Lifestyle Award criteria is attributed to this study.

Thus, steps/day recommendations have ranged from 10,000 to 16,500. Tudor-Locke et al. [23] assembled 17 studies that reported relative achievement (how many children met a recommendation) of these various step defined recommendations, and noted that the vast majority were based only on the Vincent and Pangrazi [27] and/or TudorLocke et al. [26] recommendations. To date, no single study has applied all available recommendations to describe pedometer data. Without a clear steps/day consensus, the purpose of this paper was to describe a sample of children from the Southwestern US in terms of meeting nine different pedometer recommendations found in the literature.

\section{Material and Methods}

This is a secondary analysis of an existing data set [5] of children from the Southwestern US. Recruitment and procedures have been described previously in detail [5] and are summarized for this study. The previous paper focused on contributions of daily activity segments to the physical activity patterns of children. The information presented herein has not been presented previously and is therefore, novel.

\section{Participants}

Participants included 786 (410 girls) children in grades 4 and 5 (age $9.6 \pm 0.7$ years). They were mostly of Caucasian $(45 \%)$ or Hispanic $(36 \%)$ ethnic backgrounds (10\% AfricanAmerican, 5\% American Indian, 4\% Asian-Pacific Islander). Using BMI growth charts (Centers for Disease Control and Prevention), $60 \%$ of children were in the healthy range, $17 \%$ overweight and $23 \%$ obese. Children were from six schools and four school districts that volunteered to participate. Approximately 850 children were recruited from a state wide physical activity project to participate, of which 97.5 agreed to participate. Written consent was provided by parents/ guardians and written assent was obtained from children prior to participation. All methodologies were approved by the University Institutional Review Board and the schools' administrators and research review boards. 


\section{Instruments}

The Yamax Digiwalker SW-200 pedometer was used for this study. This instrument is known to produce valid and reliable scores when measuring youth physical activity [17] and is the most widely used pedometer in monitoring children's physical activity.

\section{Procedures}

Children wore their pedometer for one week ( 7 consecutive days). Parents completed a brief demographic questionnaire to provide age, race/ethnicity, and grade. Weight and height were measured without shoes and with light clothing on a calibrated digital scale and stadiometer (Seca 882/214; Hanover, MD USA). The research team was present during school days to prompt children to record their steps each morning and reset their instruments for that day. Children were sent home with a recording sheet and reminder letter for parents to record their steps on weekend days. Validation checks were completed each day by every student when they arrived at school to ensure accuracy of step totals. Specifically, children answered simple yes or no questions regarding whether or not they removed their pedometers and what types of activities they participated in. Any extreme steps/day (e.g. $<1000$ or $>30,000$ ) values were checked with children onsite (by asking them to explain their activity to ensure consistency with their steps/day) to ensure quality of the data. Children that removed their pedometer for more than two hours (excluding sleeping/water activities) were not included for that day.

\section{Data Treatment and Analysis}

A minimum of three days [27] of recorded pedometer data were required to be included in the analyses; 786 (95\%) of the original 829 children met this requirement. Mean steps/day were calculated and the percentage of children meeting each of the nine step recommendations was computed. ANOVA's and/or t tests were used to examine differences between steps counts by gender and BMI category.

\section{Results}

Children averaged 11,113 $\pm 3,666$ steps/day. Boys were more active than girls, taking $12,088 \pm 3895$ vs. $10,218 \pm 3195$ steps/day, $\Delta=1,870$ steps/day $(p<0.01)$. Children in the normal weight category averaged $11,527 \pm 3,550$ steps/day compared to the overweight $(10,742 \pm 3,463 ; \Delta=-785$ (normal) steps/day) and obese $(10,199 \pm 3,602 ; \Delta=-1,328$ (normal) steps/day) groups. ANOVA results indicated a significant difference $(\mathrm{p}<.001)$ by weight category with Bonferroni post-hoc results revealing the differences were between the normal and obese groups.

Sixty-one percent of children met the lowest recommendation of 10,000 steps/day and $8 \%$ met the highest recommendation of 16,500 steps/day. Boys met the various step recommendations between 14 and $72 \%$ of the time and girls between 2 and $52 \%$ of the time. Table 2 illustrates the percentage of children meeting each recommendation by gender.

Table 2. Percentage of boys and girls meeting each

\begin{tabular}{lcc}
\hline Recommendation & $\begin{array}{c}\text { Boys } \\
(\mathrm{n}=376)\end{array}$ & $\begin{array}{c}\text { Girls } \\
(\mathrm{n}=410)\end{array}$ \\
\hline Tudor-Locke et al.[24] & 72 & 52 \\
Laurson et al. [15] & 52 & 52 \\
Colley et al. [8] & 45 & 27 \\
Vincent et al.[25] & 34 & 38 \\
Rowlands and Eston [22] & 34 & 27 \\
Tudor-Locke et al. [24] & 19 & 27 \\
Duncan et al. [11] & 15 & 18 \\
Craig et al. [9] & 19 & 7 \\
Craig et al. [9] & 14 & 2 \\
\hline
\end{tabular}

Table 3. Percentage of children by ethnicity meeting each recommendation

\begin{tabular}{lccccc}
\hline Recommendation & $\begin{array}{c}\text { African- } \\
\text { American } \\
(\mathrm{n}=73)\end{array}$ & $\begin{array}{c}\text { Asian/Pacific } \\
\text { Islander } \\
(\mathrm{n}=27)\end{array}$ & $\begin{array}{c}\text { Caucasian } \\
(\mathrm{n}=335)\end{array}$ & $\begin{array}{c}\text { Hispanic } \\
(\mathrm{n}=267)\end{array}$ & $\begin{array}{c}\text { Native } \\
\text { American } \\
(\mathrm{n}=39)\end{array}$ \\
\hline Tudor-Locke et al.[24] & 63 & 67 & 62 & 64 & 35 \\
Laurson et al. [15] & 52 & 59 & 50 & 55 & 35 \\
Colley et al. [8] & 37 & 33 & 47 & 41 & 31 \\
Vincent et al.[25] & 37 & 33 & 34 & 40 & 28 \\
Rowlands and Eston [22] & 33 & 26 & 27 & 35 & 26 \\
Tudor-Locke et al. [24] & 25 & 26 & 20 & 27 & 15 \\
Duncan et al. [11] & 18 & 26 & 14 & 20 & 8 \\
Craig et al. [9] & 14 & 22 & 9 & 15 & 10 \\
Craig et al. [9] & 7 & 15 & 7 & 11 & 3 \\
\hline
\end{tabular}


Table 4. Percentage of children meeting step recommendations by BMI group

\begin{tabular}{lccc}
\hline Recommendation & $\begin{array}{c}\text { Healthy } \\
\text { weight } \\
(\mathrm{n}=525)\end{array}$ & $\begin{array}{c}\text { Over- } \\
\text { weight } \\
(\mathrm{n}=149)\end{array}$ & $\begin{array}{c}\text { Obese } \\
(\mathrm{n}=202)\end{array}$ \\
\hline Tudor-Locke et al.[24] & 66 & 55 & 52 \\
Laurson et al. [15] & 56 & 45 & 44 \\
Colley et al. [8] & 41 & 30 & 30 \\
Vincent et al.[25] & 40 & 31 & 25 \\
Rowlands and Eston [22] & 34 & 26 & 21 \\
Tudor-Locke et al. [24] & 27 & 20 & 15 \\
Duncan et al. [11] & 23 & 12 & 10 \\
Craig et al. [9] & 15 & 10 & 9 \\
Craig et al. [9] & 9 & 6 & 5 \\
\hline
\end{tabular}

Table 3 illustrates the number of children meeting each recommendation by ethnicity. Healthy weight children met recommendations between $9-66 \%$ of the time compared to $6-55 \%$ (overweight) and 5-52\% (obese). Table 4 illustrates the percentage of children meeting the recommendations by BMI group.

\section{Discussion}

Overall, $61 \%$ of children ( $72 \%$ boys; $52 \%$ girls) met the lowest standard (originally an adult recommendation) of 10,000 steps/day, $52 \%$ of children met the lowest childbased standard of 11,500 (boys) and 10,000 (girls) steps/day and $8 \%$ ( $14 \%$ boys; $2 \%$ girls) met the highest recommendation of 16,500 steps/day. These numbers are lower in children who are overweight or obese with only $50 \%$ of the overweight/obese sample accumulating 10,000 steps/day and only $5 \%$ meeting the highest recommendation. A lower percentage of children in the current sample met the 10,000 steps/day recommendation than a similar aged group of primarily Caucasian Midwest US children [15]; who met the recommendation $82 \%$ of the time.

Seven of the nine recommendations examined were based primarily on international children. Laurson et al. [15] and Vincent and Pangrazi [27] are the lone studies to base their recommendations solely on US samples. It is important to note that the Laurson et al. [15] recommendation was based on a sample of both weekday and weekend data, whereas the Vincent and Pangrazi [27] recommendation was based on data that did not include weekend days. Previous research has suggested that elementary aged children are significantly less active on weekend days [6], sug- gesting the importance of considering both weekdays and weekends when examining physical activity.

In the current sample $52 \%$ of children met the Laurson et al.[15] recommendation and $34 \%$ of boys and $38 \%$ of girls met the criteria set forth by Vincent and Pangrazi[27] (13,000 boys; 11,000 girls). This is slightly less than the children in two previous US studies that reported $41-45.6 \%$ elementary school children $[15,21]$ met the same criteria. US high school [29] aged youth met this recommendation less than $25 \%$ of the time. Importantly, US children are meeting this recommendation at a lower percentage when compared to elementary aged children in Sweden (8283\%; [20]), Belgium (77\%; [7]), the United Kingdom (UK) (62-69\%; [22]) and Australia (49-52\%; [16]).

Laurson and colleagues [15] in their sample of US elementary school children found that $23.2 \%$ (boys) and $31.5 \%$ (girls) met the Tudor-Locke et al. [26] recommendation. Craig et al. [9] reported that Canadian children met this recommendation at the rates of $23 \%$ (boys) and $33 \%$ (girls). The current sample of US children met the same recommendation 19\% (boys) and 27\% (girls) of the time. Both US samples met the recommendations at a lower percentage than children from Belgium (63\%; [7]), Sweden (6090\%; [19]), UK (29-47\%; [12]), and Australia (30\%; [16]).

Similarly, the current sample of children reached 15,000 steps/day, 19 and 7\% of the time for boys and girls, respectively. This is slightly less than Canadian children where they reached 15,000 steps/day $23 \%$ (boys) and 12\% (girls) of the time [9]. Furthermore 14\% (boys) and 2\% (girls) reached 16,500 steps/day in the current sample. Craig and colleagues [9] reported that $14 \%$ and $6 \%$ of Canadian children reached this recommendation.

Recent reviews $[1,25]$ of expected pedometer values in children have suggested that boy's average between $12,000-16,000$ steps/day and girls average 10,000-13,000 steps/day. Furthermore, children from the US regularly show lower daily step values when compared to children from around the world [1]. For example, a large study [28] examining the steps/day of children living in Sweden, Australia, and the US found that Swedish children accumulated between 15,673-18,346 (boys) and 12,041-14,825 (girls) steps/day compared to Australian (13,864-15,023, boys; 11,221-12,322, girls) and US (12,554-13,872, boys; $10,661-11,383$, girls) steps/day. Children in this study accumulated a daily step average of 12,088 (boys) and 10,218 (girls) just above the lowest threshold for these expected values $[1,25]$ and slightly less than previous US studies [5,27].

More recently, Tudor-Locke et al. [23] reported that 60 minutes of MVPA in elementary aged children was accumulated (based on previous self-report [7] and 
triaxial MVPA [22]data) in 13,000-15,000 steps/day for boys and 11,000-12,000 steps/day for girls. Using these suggested values, between $19-34 \%$ of boys and $27-38 \%$ of girls in the current sample are accumulating 60 minutes of MVPA/day. Colley and colleagues [8] suggested that $12,000 \mathrm{steps} /$ day is equivalent to 60 minutes of MVPA (based on a comparison of pedometer and accelerometer counts). Less than $33 \%$ of girls and $50 \%$ of boys are accumulating 60 minutes of MVPA when using this standard.

There are a couple of limitations that are important to note. First, although the sample may be representative of children living in the Southwest US, it may not be for children in other parts of the country/world. Future studies with a larger sample of African-American, AsianAmerican, and Native American children would also add to the generalizability of these findings. Furthermore, Yamax Digiwalker pedometers are spring-levered (and although most of these recommendations are based on spring-levered pedometers) previous findings have suggested that these may underestimate steps in overweight or obese participants (at least in adults [10]).

\section{Conclusions}

With the popularity of the pedometer for measuring physical activity and the growing number of steps/day recommendations, it is important to explore the percentage of children meeting various step recommendations to determine which populations need the greatest attention. This is the first study (to our knowledge) to determine percentages of children meeting all available steps/day recommendations. Without a clear steps/day consensus this paper highlights the variability in the percentage of youth meeting recommendations. Children in the current sample are not getting enough daily activity to meet the majority of step recommendations. When the recommendations are the same for both boys and girls, more boys are meeting the recommendation than girls. However, when there are gender-specific recommendations, more girls tend to meet their recommendation. Only about $33 \%$ of children are accumulating 60 minutes of MVPA and only $36 \%$ of children are accumulating enough physical activity to qualify for the Presidential Active Lifestyle Award. Further, $50 \%$ of children identified as overweight or obese are accumulating 10,000 steps/day, 23\% are meeting BMI referenced [26] recommendations and $15-18 \%$ are meeting body fat percentage [11] recommendations. Ethnic background appears to play little role on the percentage of youth meeting recommendations.

Regardless of the standard used, US children appear to compare unfavorably to step data collected from international children, suggesting a continued effort to implement physical activity programming in schools and in the home/community is needed. Furthermore, this study high- lights difficulty that researchers and practitioners might have in choosing an appropriate recommendation (from the 9 available). This highlights the need for the research community to develop a consensus statement.

\section{References}

1. Beets M.W., D.Bornstein, A.Beighle, B.J.Cardinal, C.Morgan (2010) Pedometer-measured physical activity patterns of youth: A 13 country review. Am.J. Prev.Med. 38:208-216. 10.1016/j.amepre.2009.09.045

2. Beighle A., R.P.Pangrazi (2006) Measuring children's activity levels: The association between step-counts and activity time. J.Phys.Act.Health. 3:221-229.

3. Brusseau T.A. P.H.Kulinna, T.Kloeppel, M.Ferry (2012) Seasonal variation of American Indian Children's school-day physical activity. Biomed.Hum.Kin. 4:76-81. 10.2478/v10101012-0015-Z

4. Brusseau T.A., P.H.Kulinna, C.Tudor-Locke, M. Ferry (2013) Daily Physical Activity Patterns of Children Living in an American Indian Community. J.Phys.Act.Health. 10:48-53.

5. Brusseau T.A., P.H.Kulinna, C.Tudor-Locke, M.Ferry, H.van der Mars, H, P.W.Darst (2011) Pedometer-determined segmented physical activity patterns of fourth- and fifth-grade children. J.Phys.Act.Health. 8:279-286.

6. Brusseau T.A., P.H.Kulinna, C.Tudor-Locke, H.van der Mars, P.W.Darst (2011) Children's step counts on weekend, physical education, and non physical education days. J.Hum.Kin. 27:123-134. 10.2478/v10078-011-0010-4

7. Cardon G.M., I.M.M.De Bourdeaudhuij (2004) A pilot study comparing pedometer counts with physical activity minutes in elementary school children. Ped.Exerc.Sci. 16:355-367.

8. Colley R.C., I.Janssen, I, M.S.Tremblay (2012) Daily step target adherence to physical activity guidelines in children. Med.Sci.Sports.Exerc. 44:977-982. 10.1249/MSS.0b013e31823 f23b1

9. Craig C.L., C.Cameron, J.M.Griffiths, C.Tudor-Locke (2010) Descriptive epidemiology of youth pedometer-determined physical activity. Med.Sci.Sports.Exerc. 42:1639-1643.

10.1249/MSS.0b013e3181d58a92

10. Crouter S.E., P.L.Schneider, D.R.Bassett Jr (2005) Springlevered versus piezo-electric pedometer accuracy in overweight and obese adults. Med.Sci.Sports.Exerc. 37:1673-1679.

11. Duncan J.S., G.Schofield, E.K.Duncan (2007) Step count recommendations for children based on body fat. Prev.Med. 44:42-44.

12. Duncan M.J., Y.Al-Nakeeb, L.Woodfield, M.Lyons (2007) Pedometer-determined physical activity levels in primary school children from central England. Prev.Med. 44:416-420.

10.1016/j.ypmed.2006.11.019

13. Epstein L.H., R.A.Paluch, L.E.Kalakanis, G.S.Goldfield, F.J.Cerny, J.N.Roemmich (2001) How much physical activity do youth get? A quantitative review of heart-rate measured activity. Ped. 108:e44.

14. Kohl H.W., C.L.Craig, E.V.Lambert, S.Inoue, J.R.Alkandari, G.Leetongin, S.Kahlmeier (2012) The pandemic of physical inactivity: global action for public health. Lancet. 380:294-305.

10.1016/S0140-6736(12)60898-8

15. Laurson K.R., J.C.Eisenmann, G.J.Welk, E.E.Wickel, D.Gentile, D.A.Walsh (2008). Evaluation of youth pedometerdetermined physical activity guidelines using receiver operator characteristic curves. Prev.Med. 46:419-424. 10.1016/j.ypmed. 2007.12.017 
16. Lubans D., P.Morgan (2008) Evaluation of an extracurricular school sport programme promoting lifestyle and life time activity for adolescents. J.Sports Sci. 26:519-529.

10.1080/02640410701624549

17. McKee D.P., C.A.G.Boreham, M.H.Murphy, A.M.Nevill (2005) Validation of the Digiwalker pedometer for measuring physical activity in young children. Ped.Exerc.Sci. 17:345-352.

18. President's Council on Physical Fitness and Sports (2012)

The Presidents Challenge: Physical Activity and Fitness Awards; Available from www.presidentschallenge.org.

19. Raustorp A., J.Ludvigsson (2007) Secular trends of pedometer-determined physical activity in Swedish school children. Acta.Paed. 96:1824-1828. 10.1111/j.1651-2227.2007.00525.x

20. Raustorp A., R.P.Pangrazi, A.Stahle (2003) Physical activity level and body mass index among schoolchildren in south-eastern Sweden. Acta.Paed. 93:400-404. 10.1111/j.16512227.2004.tb02969.x

21. Reed J.A., S.W.Brittenham, D.A.Phillips, C.S.Carlisle (2007) A preliminary examination of the fitness levels of children who meet the president's council physical activity recommendation. Phys.Edu. 64:159-167.

22. Rowlands A.V., R.G.Eston (2005) Comparison of accelerometer and pedometer measures of physical activity in boys and girls, ages 8-10 years. Res.Q.Exerc.Sport. 76:251-257.

10.5641/027013605X13080719840591

23. Tudor-Locke C., C.L.Craig, M.W.Beets, S.Belton,

G.M.Cardon, S.Duncan, Y.Hatano, D.R.Lubans, T.S.Olds,

A.Raustorp, D.A.Rowe, J.C.Spence,.S.Tanaka, S.N.Blair (2011) How many steps/day are enough? For children and adolescents. Int.J.Beh.Nutr.Phys.Act. 8:78. 10.1186/1479-5868-8-78
24. Tudor-Locke C., Y.Hatano, R.P.Pangrazi, M.Kang (2008)

Revisiting "How many steps per day are enough?"

Med.Sci.Sports.Exerc. 40:S537-S543.

10.1249/MSS.0b013e31817c7133

25. Tudor-Locke C., J.J.McClain, T.Abraham, S.B.Sisson,

T.L.Washington (2009) Expected values for pedometerdetermined physical activity in youth. Res.Q.Exerc.Sport. 80:164 174. 10.5641/027013609X13087704028075

26. Tudor-Locke C., R.P.Pangrazi, C.B.Corbin, et al. (2004). BMI referenced standards for recommended pedometerdetermined steps/day in children. Prev.Med. 38:857-864.

27. Vincent S.D., R.P.Pangrazi (2002) An examination of the activity patterns of elementary school children. Ped.Exerc.Sci. 14:432-441.

28. Vincent S.D., R.P.Pangrazi, A.Raustorp, L.M.Tomson, T.F.Cuddihy (2003) Activity levels and body mass index of children in the United States, Sweden, and Australia.

Med.Sci.Sports.Exerc. 35:1367-1373.

29. Zizzi S., E.Vitullo, J.Rye, N.O’Hara-Tompkins, C.Abiliso B.Fisher, M.Bartlett (2006) Impact of a three-week pedometer intervention on high school students' daily step counts and perceptions of physical activity. Am.J.Health.Educ. 37:35-40.

Received 11.03.2013

Accepted 14.06.2013

(c) University of Physical Education, Warsaw, Poland 